Virginia Commonwealth University vCU Scholars Compass

2014

\title{
Efficacy of a Workbook to Promote Forgiveness: A Randomized Controlled Trial with University Students
}

Quandrea Harper

Everett L. Worthington

Virginia Commonwealth University, eworth@vcu.edu

Brandon J. Griffin

Virginia Commonwealth University, griffinb2@vcu.edu

See next page for additional authors

Follow this and additional works at: https://scholarscompass.vcu.edu/psyc_pubs

Part of the Psychology Commons

\section{Downloaded from}

https://scholarscompass.vcu.edu/psyc_pubs/41

This Article is brought to you for free and open access by the Dept. of Psychology at VCU Scholars Compass. It has been accepted for inclusion in Psychology Publications by an authorized administrator of VCU Scholars Compass. For more information, please contact libcompass@vcu.edu. 


\section{Authors}

Quandrea Harper, Everett L. Worthington, Brandon J. Griffin, Caroline R. Lavelock, Joshua N. Hook, Scott Vrana, and Chelsea Greer 
Efficacy of a Workbook to Promote Forgiveness:

A Randomized Controlled Trial with University Students

Quandrea Harper, Everett L. Worthington, Jr., Brandon J. Griffin, Caroline R. Lavelock, Joshua N. Hook, Scott R. Vrana, \& Chelsea L. Greer

\section{Author Note}

Correspondence concerning this article should be addressed to Everett L.

Worthington, Jr., Box 842018, 806 West Franklin Street, Department of Psychology, Virginia Commonwealth University, Richmond, VA 23284-2018. We acknowledge support from the Fetzer Institute for two grants to Worthington that supported portions of this project. Email: eworth@vcu.edu

\section{Target Journal: Journal of Clinical Psychology}

This is the peer reviewed version of the following article: Harper, Q., Worthington, E. L., Griffin, B. J., Lavelock, C. R., Hook, J. N., Vrana, S. R. and Greer, C. L. (2014), Efficacy of a Workbook to Promote Forgiveness: A Randomized Controlled Trial With University Students. J. Clin. Psychol., 70: 1158-1169, which has been published in final form at http://dx.doi.org/10.1002/jclp.22079. This article may be used for non-commercial purposes in accordance With Wiley Terms and Conditions for self-archiving 


\begin{abstract}
Objective

The present study investigated the efficacy of a six-hour self-directed workbook adapted from the REACH Forgiveness intervention.

\section{Method}

Undergraduates $(N=41)$ were randomly assigned to either an immediate treatment or wait-list control condition. Participants were assessed across three time periods using a variety of forgiveness outcome measures.
\end{abstract}

\title{
Results
}

The six-hour workbook intervention increased forgiveness, as indicated by positive changes in participants' forgiveness ratings that differed by condition. In addition, benchmarking analysis showed that the self-directed workbook intervention is at least as efficacious as the delivery of the REACH Forgiveness model via group therapy.

\section{Conclusion}

A self-directed workbook intervention adapted from the REACH Forgiveness intervention provides an adjunct to traditional psychotherapy that could assist the mental health community to manage the burden of unforgiveness among victims of interpersonal harm.

Words: 127

Key Words: Forgiveness, Intervention, Positive Psychology, self-directed, workbook 


\section{Efficacy of a Workbook to Promote Forgiveness:}

\section{A Randomized Controlled Trial with University Students}

Empirical investigations of forgiveness, its causes, and its correlates continue to rapidly accrue (for a meta-analytic review, see Fehr, Gelfand, \& Nag, 2010), and theorists often interpret this growing literature using an adapted stress-and-coping model (Lazarus, 1999; Strelan \& Covic, 2006; Worthington, 2006). Proponents of the model suggest that offenses may function as stressors that trigger evaluative appraisals and stress responses among victims of interpersonal harm. Furthermore, Worthington (2006) adduced evidence suggesting that forgiveness entails replacing negative unforgiving emotions (i.e., bitterness, anger, fear) toward an offender with positive other-oriented emotions (i.e., love, compassion, sympathy, or empathy). Decreases in negative emotion and increases in positive emotion are each mechanisms by which forgiveness may improve physical, mental, relational, and spiritual health outcomes (Green, Decourville, \& Sadava, 2012; Harris \& Thoresen, 2006; Pressman, Gallagher, \& Lopez, 2013; Worthington, Witvliet, Pietrini, \& Miller, 2007).

Given the benefits associated with forgiveness, a variety of interventions have been developed to facilitate interpersonal forgiveness among victims of offenses (e.g., Enright \& Fitzgibbons, 2000; Luskin, 2003; Rye, Pargament, Pan, Yingling, Shogren, \& Ito, 2005; Worthington, 2006). In 2005, Wade, Worthington, and Meyer metaanalytically reviewed investigations of forgiveness interventions. They concluded that forgiveness interventions effectively promoted forgiveness beyond shared common curative factors. While Wade et al. did not find that any specific forgiveness intervention was superior to another, they determined that the extent to which participants benefited 
from forgiveness interventions was directly related to the amount of time that participants spent in treatment, such that the effect of treatment appeared to strengthen as the duration of the intervention increased.

The content of interventions designed to promote interpersonal forgiveness has changed little since the time of Wade et al.'s review; yet, scholars continue to call for interventions that are applicable to a broad array of settings (i.e., healthcare, military, couples counseling) and that produce long-lasting effects (Cohn \& Frederickson, 2010; Harris \& Thoresen, 2006; Wade, Worthington, \& Haake, 2009). Recently, Wade, Hoyt, and Worthington (2013) meta-analyzed 67 randomized clinical trials (RCTs) of interventions promoting forgiveness. Their conclusion was similar to that of Wade et al. They found no differences in efficacy across interventions, as well as a strong effect of duration of treatment on change in forgiveness.

In the present study, we focus on the REACH Forgiveness intervention (Worthington, 2006). According to this model, participants are led through five steps to REACH Forgiveness: R=Recall the Hurt, E=Empathize with the Offender, A=Give an Altruistic Gift of Forgiveness, $\mathrm{C}=$ Commit to the Forgiveness Experience, and $\mathrm{H}=\mathrm{Hold}$ on to Forgiveness When Doubt Occurs. The REACH Forgiveness intervention is primarily intended to facilitate emotional forgiveness (i.e., replacement of unforgiving emotions with positive other-oriented emotions) that may or may not be accompanied by decisional forgiveness (i.e., a behavioral intention to treat the offender as a worthwhile person of value; see Exline, Worthington, Hill, \& McCullough, 2003). The efficacy of the REACH Forgiveness intervention is supported across a range of non-religious samples including individuals (McCullough, Worthington, \& Rachal, 1997), couples (Ripley \& 
Worthington, 2002), and parents (Kiefer et al., 2010), as well as religious adults in the Philippines (Worthington et al., 2010). It is routinely delivered via individual, couple, or group formats over the course of six hours, though it may be modified for any duration from 3 to 20 hours. Additional information regarding the REACH Forgiveness intervention may be obtained online (http://www.people.vcu.edu/ eworth/).

Although clinical settings such as individual, couple, and group therapy frequently provide valuable opportunities for people to enjoy emotionally corrective experiences related to an offense within the context of an interpersonal framework, a variety of limitations exist within traditional delivery methods of mental health services. For example, only people who are able to devote several hours attending therapy can feasibly obtain access to the existing psycho-educational interventions that are designed to promote forgiveness. In fact, this problem pervades the delivery of treatment services within the entire mental health community. Kazdin and Rabbitt (2013) therefore critique traditional delivery methods of mental health treatment as insufficient to meet the immense burden of mental illness within society. They challenge interventionists to develop programs that may be more easily disseminated to populations who are difficult to access and that may be administered by care providers who possess fewer professional credentials than the expertise that is typically required to conduct psychotherapy. In summary, psychotherapists need evidenced-based forgiveness interventions that can be easily disseminated and that might be used as adjuncts to traditional psychotherapy.

In the present study, we tested an adaptation of the REACH Forgiveness intervention in the format of a 6-hour self-directed workbook (Worthington, Lavelock, \& Scherer, 2012). The workbook combines both psycho-educational instruction and 
experiential exercises in order to facilitate forgiveness among victims of interpersonal harm. The efficacy of the REACH Forgiveness workbook was examined between two conditions (immediate treatment vs. waitlist control) across three time periods.

Hypotheses for the present study are as follows.

1. Greater forgiveness ratings will be observed within participants' repeated assessments after completing the workbook intervention relative to before completing the workbook.

2. Efficacy of the REACH Forgiveness intervention delivered via a selfdirected workbook will be at least as efficacious as past trials delivering the intervention via psycho-educational groups.

\section{Method}

\section{Participants}

Undergraduates $(N=41)$ at a large Mid-Atlantic public university volunteered to participate in this study. Participants were required to be at least 18 years old and to report feeling unforgiveness toward another person. Students who finished the study ( $N=$ 39) did not differ from those who dropped out $(n=2)$ on any of the forgiveness variables at initial administration, based on one-way ANOVAs: TRIM ( $p=.998)$, EFS: $(p=.543)$, DFS: $(p=.771)$, and RFS: $(p=.837)$. Those who completed the entire study, including a workbook intervention and assessments at three time points, were awarded credit to satisfy a curriculum requirement for research participation.

The mean age for participants was 19.64 years $(S D=3.10)$, and the sample was 78\% female. Participants reported a variety of racial backgrounds, including White (48\%), Black (17\%), Asian/Pacific Islander (14\%), Latino/Latina (10\%), multiracial 
(7\%), and Arab (5\%). With respect to religion, most participants identified as Christian $(69 \%)$ and some as atheist/agnostic (10\%), Muslim (5\%), or none $(17 \%)$.

\section{Design}

A wait-list control intervention design was employed in the present study. Researchers randomly assigned students to either the Immediate Treatment condition (IT; $n=24$ ) or the Wait-list Control condition (WC; $n=25$ ). Pairs of participants were randomly assigned to condition and yoked to each other for timing of assessments. Participants also completed measures of demographic variables during the initial observation $\left(\mathrm{O}_{\mathrm{D}}\right)$, and the outcome variables were assessed at three sequential time points: upon entry to the study $\left(\mathrm{O}_{1}\right)$, approximately two weeks after entry $\left(\mathrm{O}_{2}\right)$, and approximately four weeks after entry $\left(\mathrm{O}_{3}\right)$. All assessments and the intervention were administered online. Using Campbell and Stanley's notation (1966), in which the X denotes the workbook intervention, the waiting-list design can be represented as follows.

$\begin{array}{cccccc}\mathrm{O}_{\mathrm{D}} \mathrm{O}_{1} & \mathrm{X} & \mathrm{O}_{2} & & \mathrm{O}_{3} & \text { (Immediate Treatment; IT) } \\ \mathrm{O}_{\mathrm{D}} \mathrm{O}_{1} & & \mathrm{O}_{2} & \mathrm{X} & \mathrm{O}_{3} & \text { (Waitlist Control; WC) }\end{array}$

\section{Workbook}

Researchers adapted a self-directed workbook intervention (Worthington, Lavelock, \& Scherer, 2012) from the empirically supported REACH Forgiveness group psycho-education manuals developed by Worthington (2006). The workbook contains six sections in which participants engage in multi-modal exercises that together require approximately six hours to complete. The goal of the first two sections of the workbook is to introduce participants to the idea that forgiveness may be decisional and/or emotional (Exline, Worthington, Hill, \& McCullough, 2003; Worthington, Hook, Utsey, 
Williams, \& Neil, 2007) and to inform the reader that the focus of the workbook is to facilitate emotional forgiveness by assisting victims in replacing negative emotions (i.e., anger, fear, bitterness) toward an offender with positive emotions (i.e., empathy, compassion; Worthington, 2006). The subsequent sections guide the participant through making a decision to forgive the offender, and working systematically through the five steps to REACH emotional forgiveness: Recall the Hurt, Empathize with the Offender, Give an Altruistic Gift, Commit to Forgiveness, and Hold on to Forgiveness (for further reading on the REACH Forgiveness model, see Worthington, 2006).

\section{Measures}

\section{Transgression Related Interpersonal Motivation Inventory (TRIM;}

McCullough, Fincham, \& Tsang, 2003). Students' interpersonal motivations toward their offenders were measured using the TRIM Inventory (McCullough et al., 1998, 2003). The TRIM Inventory used in the present study is comprised of two subscales. The subscales measure unforgiving motivations toward offenders, using five items to assess vengeful motivations (i.e., "I'll make him/her pay”) and seven items to assess avoidant motivations (i.e., "I live as if he/she doesn't exist, isn't around”). Participants rated each item on a 5-point rating scale from $1=$ strongly agree to $5=$ strongly disagree, such that higher scores on vengeful and avoidant motivations indicated more unforgiveness. In the present study, the revenge and avoidance subscales were summed (TRIM-AR), which had Cronbach's alpha between $\alpha=.91$ to .92 across time points.

\section{Decisional Forgiveness Scale (DFS; Worthington, Hook, Utsey, Williams, \&}

Neil, 2007). The DFS is composed of eight items that are designed to measure the degree to which participants have made a decision to forgive an offender of a specific offense 
(i.e., "If I see him or her, I will act friendly"). Participants rated their level of agreement to each prompt using a rating scale from $1=$ strongly disagree to $5=$ strongly agree . Higher scores on the DFS indicate greater levels of forgiveness. In the present study, Cronbach's alphas for the DFS ranged between .79 and .91 across time points.

\section{Emotional Forgiveness Scale (EFS; Worthington, Hook, Utsey, Williams, \&}

Neil, 2007). The EFS assesses the extent to which participants report feeling emotional forgiveness toward an offender. An example of an item on this scale is "I feel sympathy toward him or her." The scale is comprised of eight items on which participants rate their agreement with a prompt using a rating scale $(1=$ strongly disagree, $5=$ strongly agree $)$. Higher scores on the EFS represent greater levels of forgiveness. Cronbach's alpha ranged between $\alpha=.80$ to .81 across time points.

Rye Forgiveness Scale (RFS; Rye et al. 2001). The RFS examines participants' degree of forgiveness toward an offender regarding a specific offense. Items on the RFS may be categorized according to either the absence of negative thoughts, feelings, and behaviors toward an offender (i.e., "I spend time thinking about ways to get back at the person who wronged me") or the presence of positive thoughts, feelings, and behaviors toward the offender (i.e., "If I encountered the person who wronged me, I would feel at peace"). Both subscales were combined in the present study. The RFS has 15 items, and participants rate each item using a rating scale from $1=$ strongly disagree to $5=$ strongly agree. Participants' responses were coded such that higher scores indicated a greater degree of forgiveness. Cronbach's alphas ranged between .88 and .93 across time points. 


\section{Procedure}

Students were recruited using an online participant pool administrated by SONA Systems@. Those who met the criteria for inclusion were yoked with another participant by the researchers, and members of each dyad were randomly assigned to either the Immediate Treatment or Wait-list Control conditions. The demographic questionnaire and the first outcome assessment were then delivered to each participant via email. After both members of the dyad returned the assessments, the student assigned to the IT condition was sent the workbook intervention to complete within two weeks. After two weeks elapsed (and the IT participant had returned the completed workbook), the researcher then sent the second outcome assessment to both participants. Next, the workbook intervention was sent to the student assigned to the $\mathrm{WC}$ condition. Two weeks later (after the student in the WC condition returned the workbook), the final outcome assessment was administered to both participants. The final outcome assessment served as a follow up assessment for the IT condition and post-test assessment for the WC condition. A detailed CONSORT flow chart is presented in Figure 1.

\section{Data Analysis Plan}

Our aim was to evaluate the efficacy of a 6-hour workbook intervention designed to promote forgiveness of a specific interpersonal offense. Given the dependency within the data, which are repeated measures nested within individual participants, the data were analyzed by computing multilevel models for each of the outcome variables (TRIM, EFS, DFS, \& RFS). Multilevel modeling was the preferred analytic strategy because it accommodates the inherent dependency within the data and allows for person-level variability. The analytic strategy used in the current analyses involved three repeated 
measures (level 1) nested within each person (level 2). The basic multilevel model took the following form, where $\mathrm{i}$ indexes time and $\mathrm{j}$ indexes individuals.

Level 1 (repeated measures):

$$
Y_{\text {Forgiveness }}=\beta_{0 j}+\beta_{1 j} t_{i m e} e_{i j}+r_{i j}
$$

Level 2 (individuals)

$$
\begin{aligned}
& \beta_{0 j}=\gamma_{00}+\gamma_{01} \text { condition }_{j}+u_{0 j} \\
& \beta_{1 j}=\gamma_{10}+\gamma_{11} \text { condition }_{j}+u_{1 j}
\end{aligned}
$$

In addition, to demonstrating the efficacy of the self-directed workbook, we also aimed to show that delivery of the REACH Forgiveness intervention via a self-directed workbook is at least as effective as delivery via a psycho-educational group, when the duration of treatment is approximately the same. We used standardized change scores from seven studies that are similar to the present study, with the exception that the REACH Forgiveness intervention was delivered via psycho-educational groups in the comparison studies. Studies included for comparison (1) were clinical trials that implemented the REACH Forgiveness model, (2) had a duration of treatment between 6 and 9 hours, (3) had participants' mean age greater than 18 years old, (4) had interventions administered to a general audience as opposed to couples, parents, etc., and (5) were published in English in a peer-reviewed journal. See Table 2 for reference of the seven comparison studies.

\section{Results}

\section{Preliminary Data Analysis}

Cleaning of data. Because less than $5 \%$ of the data was missing, problems associated with missing data were not considered to be serious (Tabachnick \& Fidell, 
2001). In addition, given the ability of multilevel modeling to handle incomplete data that are collected over a series of repeated measures, participants who dropped out of the study were retained in the final analyses. Outliers $(n=3)$ were identified and adjusted to one unit higher than the next highest value to preserve the order of the data and to reduce the influence of outliers on the results. Means and standard deviations for both treatment conditions (IT v. WC) across all three time periods (t1, t2, t3) are reported in Table 1.

Initial equivalence of conditions. To ensure equivalence of immediate treatment and waiting-list conditions, we conducted a one-way (Condition; IT or WL) multivariate analysis of variance (MANOVA), using participants' ratings on the initial administration of the outcome variables (i.e., TRIM, EFS, DFS, \& RFS). These did not differ significantly between conditions, multivariate $F(4,36)=.53, p=.714$. In addition, to ensure that the selected transgressions were not significantly different initially, we conducted an independent samples t-test (IT vs. WC) on the participants' rating of singleitem hurtfulness $(1=$ Not at all Hurtful, $5=$ Extremely Hurfful $)$. Self-rated hurtfulness of the offense did not differ significantly between conditions, $t(39)=.755, p=.455$. The random assignment to conditions was deemed equivalent according to person variables and also perceived hurtfulness of transgressions.

Manipulation check on participation in completing the workbooks. Data were collected to examine the fidelity with which the self-directed workbook was administered. The mean time to complete the workbook was 7.02 ( $\mathrm{SD}=3.22$ ) hours, according to participants' self-report. The mean number of words that students typed was $4,136(\mathrm{SD}=2,649)$ with a range of 126 to 14,649 . That being said, only two students wrote fewer than 1,000 words. We compared the pre-test scores of students who wrote 
fewer than 1,000 words with those who wrote 1,000 or more words by performing oneway ANOVAs on each forgiveness outcome (TRIM, DFS, EFS, \& RFS). We found that those who wrote fewer words initially reported experiencing less unforgiveness (TRIM: $F(1,40)=5.54, p=.024, M=15.50<M=35.25)$ and more forgiveness on one of three outcome variables (DFS: $F(1,40)=3.05, p=.088, M=38.00>M=28.63$; EFS: $F(1$, 40) $=2.18, p=.148, M=27.50>M=20.23$; RFS: $F(1,40)=11.41, p=.002, M=69.00>$ $M=44.95)$ when compared to those that responded more thoroughly to the self-directed intervention. Nevertheless, the two students who wrote fewer than 1,000 words were retained in the final analyses in favor of a more conservative test of treatment efficacy. Also, students rated the helpfulness of the workbook with respect to eight different areas using a Likert scale (1= Not at All Helpful, $5=$ Extremely Helpful $)$. The mean helpfulness rating was $4.30(\mathrm{SD}=0.59)$. We concluded that participants, on average, devoted sufficient time to the workbook and found it to be a helpful tool to promote forgiveness.

\section{Investigation of Treatment Efficacy}

For TRIM scores, participants in the immediate treatment condition exhibited a stronger decline in unforgiveness between $\mathrm{t} 1$ and $\mathrm{t} 2$ after receiving treatment and maintained their gains at t3; whereas, participants in the waitlist condition exhibited no change in unforgiveness ratings between $\mathrm{t} 1$ and $\mathrm{t} 2$ but a decrease by $\mathrm{t} 3$ after receiving treatment. Thus, the reduction of unforgiveness over time was qualified by the condition to which participants had been randomly assigned and was curvilinear in form, $F(1$, $41.42)=7.26, p=.010$. Differences between mean scores on both conditions are displayed in Table 1, and Figure 2 Panel A graphically represents the decline of participants' unforgiveness ratings by condition. The effect size was calculated by 
comparing means divided by the pooled variance for participants in the immediate treatment and waitlist conditions at $\mathrm{t} 2$, after which those in the immediate treatment had completed the workbook and those in the waitlist condition served as a non-action control, Cohen's $d=-.56$.

For DFS scores, participants in the immediate treatment condition exhibited a stronger increase in decisional forgiveness between $\mathrm{t} 1$ and $\mathrm{t} 2$ after receiving treatment that continued until t 3 ; whereas, participants in the waitlist condition exhibited no change in decisional forgiveness between $\mathrm{t} 1$ and $\mathrm{t} 2$ but an increase by $\mathrm{t} 3$ after receiving treatment. Therefore, the increase of decisional forgiveness over time was qualified by the condition to which participants had been randomly assigned and was linear in form, $F(1,61.20)=4.24, p=.044$, although the curvilinear trend approached significance, $F(1$, 41.23) $=3.27, p=.078$. Differences between mean scores on both conditions are displayed in Table 1. The effect size for participants' ratings of decisional forgiveness was $d=.45$.

For EFS scores, participants in the immediate treatment condition exhibited a stronger increase in forgiveness between $\mathrm{t} 1$ and $\mathrm{t} 2$ after receiving treatment and maintained their gains at $\mathrm{t} 3$; whereas, participants in the waitlist condition reported no change in emotional forgiveness between $\mathrm{t} 1$ and $\mathrm{t} 2$ but an increase by $\mathrm{t} 3$ after receiving treatment. The increase of emotional forgiveness over time was qualified by the condition to which participants had been randomly assigned and was curvilinear in form, $F(1$, 41.54) $=9.16, p=.004$. Differences between mean scores on both conditions are displayed in Table 1. The effect size for participants' ratings of emotional forgiveness was $d=.50$. 
For RFS scores, participants in the immediate treatment condition exhibited a stronger increase in forgiveness between $\mathrm{t} 1$ and $\mathrm{t} 2$ after receiving treatment and maintained their gains at $\mathrm{t} 3$; whereas, participants in the waitlist condition reported no change in forgiveness between $\mathrm{t} 1$ and $\mathrm{t} 2$ but an increase by $\mathrm{t} 3$ after receiving treatment. As was the case with prior outcomes, the increase in forgiveness over time was qualified by the condition to which participants had been randomly assigned and was curvilinear in form, $F(1,41.45)=13.12, p=.001$. Differences between mean scores on both conditions are displayed in Table 1, and Figure 2 Panel B graphically represents the increase of participants' forgiveness ratings by condition as indicated by the RFS. The effect size for participants' ratings of forgiveness was $d=.69$.

\section{Comparison of the Treatment Delivery Methods}

To establish a benchmark against which we might compare the efficacy of the self-directed workbook, seven published, randomized controlled trials in which the REACH Forgiveness intervention was delivered to a general audience via group therapy were collected. Benchmarks were created using treatment outcome data from the seven studies and normative population data specific to the primary outcome measure employed by each study (cited in Table 2). The formula for computation was: $z=(x-\mu) / \sigma$, such that $x$ was the mean score for participants assigned to the immediate treatment condition in each study, $\mu$ was the population mean for the primary measure obtained from validation studies for each particular measure, and $\sigma$ was the population standard deviation for the measure also obtained from validation studies of that measure. The use of normative data to calculate $z$ scores permitted comparison across the studies. 
Sample characteristics for the seven comparison studies were mostly similar to the present study. Participants in the current study were slightly younger (19.64 years) than the average age of those who participated in the comparison studies (25.58 years), and females comprised the majority of participants in the present study (78\%) and in the studies used for comparison (75\%). As shown in Table 2, the studies collected for comparison differed from the present study in terms of modality (i.e., group therapy v. self-directed workbook) but were similar in terms of dosage (between 6-9 hours of treatment).

Standardized change scores were computed for the primary outcome measures in each of the comparison studies and in the present study by subtracting the post-treatment $z$-score from the pre-treatment $z$-score. Higher standardized scores represent greater change either by decreasing unforgiveness (if the score is negative) or increasing forgiveness (if the score is positive). In Table 2, we report the standardized change scores of each of the studies. The average standardized change score for the comparison studies was computed using the absolute value of the standardized change scores $(z=.53)$. Also, a 95\% confidence interval was computed by multiplying the standard deviation of the change scores $(\mathrm{SD}=.10)$ by 1.96 to obtain the upper $(z=.72)$ and lower limits $(z=.34)$ of the interval. Thus, a treatment could be deemed less efficacious than the comparison studies if the standardized change score was less than the lower limit, equally as efficacious if the standardized change score was between the lower and upper limits, and more efficacious if the standardized change score was greater than the upper limit.

Relative to the benchmark of standard change obtained from prior administrations of the REACH Forgiveness intervention via a psycho-educational group $(z=.53)$, change 
in the present study $(z=1.05)$ was nearly twice as large. Moreover, change in the present study was greater than the upper limit of the confidence interval, which suggests that delivery of the REACH Forgiveness intervention via a self-directed workbook is at least as efficacious, if not more so, than delivery of the intervention via psycho-educational group therapy.

\section{Discussion}

In the present study, we tested the efficacy of a six-hour, self-directed workbook that was created to facilitate forgiveness among victims of interpersonal harm. The workbook was adapted from the REACH Forgiveness intervention (Worthington, 2003), and it represents the first attempt to promote interpersonal forgiveness using a psychotherapeutic intervention other than individual or group psychotherapy. The workbook was disseminated via the Internet to undergraduates who were randomly assigned to either immediate treatment or wait-list control conditions. In particular, participants who were randomly assigned to an immediate treatment condition and who completed the workbook intervention reported greater changes in the expected directions on each forgiveness outcome that was assessed relative to participants in a wait-list control condition. Also, those in the immediate treatment condition maintained their gains two weeks after having completed the workbook.

The self-directed workbook also produced positive changes equivalent to that of face-to-face group therapy, when controlling for the duration of treatment. This finding represents an important facet of forgiveness intervention research, namely that the REACH forgiveness intervention may be efficaciously delivered via a six-hour selfdirected workbook. Nevertheless, future research is required to further examine the 
clinical utility of the forgiveness workbook. For example, Frederickson and Cohn (2010) argue that person-activity match is an important consideration when developing innovative methods of treatment delivery. The workbook might be further tested by examining what if any person-related traits and types of offenses might make one an ideal candidate (or not) to complete a forgiveness intervention via a self-directed workbook. Overall, these findings suggest that forgiveness among victims of interpersonal harm can be increased using a self-directed workbook without requiring direct therapist intervention, and they provide initial support for an self-directed workbook that may be delivered online to facilitate forgiveness among victims of offense.

\section{Limitations}

Limitations in the present study include a restrictive sample size, which resulted in low statistical power, and may have resulted in the finding that changes as indicated by aspects of forgiveness that are less emphasized by the REACH Forgiveness intervention merely approached statistical significance. Second, although the unforgiveness experienced by undergraduates is certainly worth investigating, the present workbook needs to be tested in more challenging clinical settings with a higher degree of diversity among clients (i.e., community mental health centers, hospitals, etc.). The hope is that this workbook intervention will ultimately allow people in populations that are largely inaccessible to individual or group therapy to work through forgiveness. Third, the ease with which a workbook may be disseminated online also limits researcher's ability to control treatment fidelity. Future studies might seek to qualitatively assess participants' responses to the workbook and to develop measures of fidelity beyond simply implementing a word count of participants' self-reported duration of treatment. Finally, it 
was observed that some participants did not respond as thoroughly to the workbook intervention as others, and future research is need to examine possible factors that might influence the person-activity match with respect to administering forgiveness intervention via a self-directed workbook.

\section{Conclusion}

People become victims of harm as an inevitable consequence of daily interpersonal routines. If unforgiveness surrounding these offenses is not sufficiently managed and becomes chronic in nature, then victims of offense may suffer from preventable physical, mental, relational, and spiritual impairment. The present study demonstrated that a six-hour, self-directed workbook adapted from the REACH Forgiveness intervention offers a cost-effective and easily accessible method to deliver forgiveness interventions as an adjunct to traditional psychotherapy. 


\section{References}

Campbell, D. T., \& Stanley, J. C. (1966). Experimental and quasi-experimental designs for research. Chicago, IL: Rand McNally.

Cohn, M. A., \& Fredrickson, B. L. (2010). In search of durable positive psychology interventions: Predictors and consequences of long-term positive behavior change. The Journal of Positive Psychology, 5(5), 355-366

Enright, R. D., \& Fitzgibbons, R. P. (2000). Helping clients forgive: An empirical guide for resolving anger and restoring hope. Washington D.C.: American Psychological Association.

Exline, J. J., Worthington, E. L., Jr., Hill, P. C., \& McCullough, M. E. (2003). Forgiveness and justice: A research agenda for social and personality psychology. Personality and Social Psychology Review 7, 337-348.

Fehr, R., Gelfand, M., \& Nag, M. (2010). The road to forgiveness: A meta-analytic synthesis of its situational and dispositional correlates. Psychological Bulletin, American Psychological Association, 136 (5), 894-914.

Green, M., DeCourville, N., \& Sadava, S. (2012). Positive affect, negative affect, stress, and social support mediators of the forgiveness-health relationship. Journal of Social Psychology, 152(3), 288-307.

Goldman, D. B., \& Wade, N. G. (2012). Comparison of forgiveness and anger-reduction group treatments: A randomized controlled trial. Psychotherapy Research, 22(5), 604-620.

Harris, A. H. S., \& Thoresen, C. E. (2006). Extending the influence of positive psychology interventions into health care settings: Lessons from self-efficacy and 
forgiveness. The Journal of Positive Psychology, 1(1), 27-36.

Kazdin, A. E. \& Rabbitt, M. (2013). Novel models for delivering mental health services and reducing the burdens of mental illness. Clinical Psychological Science, 1(2), $170-191$.

Kiefer, R. P., Worthington, E. L., Jr., Myers, B., Kliewer, W. L., Berry, J. W., Davis, D. E., Kilgour, J., Jr., Miller, A. J., Van Tongeren, D. R., \& Hunter, J. L. (2010). Training parents in forgiveness and reconciliation. American Journal of Family Therapy, 38, $32-49$.

Lampton, C., Oliver, G., Worthington, E.L., Jr., \& Berry, J.W. (2005). Helping Christian college students become more forgiving: An intervention study to promote forgiveness as part of a program to shape Christian character. Journal of Psychology and Theology, 33, 278-290.

Lavelock, C. R., \& Worthington, E. L., Jr. (2012). The path to forgiveness: Six practical sections for becoming a more forgiving person. Virginia Commonwealth University, Richmond.

Lazarus, R.S. (1999). Stress and emotion: A new synthesis. New York: Springer.

Luskin, F. (2002). Forgive for good: A proven prescription for health and happiness. San Francisco, CA: Harper Collins Publishers.

McCullough, M. E., Fincham, F. D., \& Tsang, J. (2003). Forgiveness, forbearance, and time: The temporal unfolding of transgression-related interpersonal motivations. Journal of Personality and Social Psychology, 84, 540-557. doi: 10.1037/00223514.84.3.540 
McCullough, M. E., Rachal, K. C., Sandage, S. J., Worthington, E. L., Jr., Brown, S. W., \& Hight, T. L. (1998). Interpersonal forgiving in close relationships: II. Theoretical elaboration and measurement. Journal of Personality and Social Psychology, 75(6). 1586-1603.

McCullough, M. E., Worthington, E. L. Jr., \& Rachal, K. C. (1997). Interpersonal forgiving in close relationships. Journal of Personality and Social Psychology, 73, 321-336.

Pressman, S. D., Gallagher, M. W., \& Lopez, S. J. (2013). Is the emotion-health connection a "First-World Problem"? Psychological Science, 24(4), 544-549.

Ripley, J. S., Worthington, E. L., Jr. (2002). Hope-focused and forgiveness-based group interventions to promote marital enrichment. Journal of Counseling and Development, 80, 452-463.

Rye, M. S., Loiacono, D. M., Folck, C. D., Olszewski, B. T., Heim, T. A., \& Madia, B. P. (2001). Evaluation of the psychometric properties of two forgiveness scales. Current Psychology, 20(3), 260-277.

Rye, M. S., Pargament, K. I., Pan, W., Yingling, D. W., Shogren, K. A., \& Ito, M. (2005). Can group interventions facilitate forgiveness of an ex-spouse? A randomized clinical trial. Journal of consulting and clinical psychology, 73(5), 880.

Sandage, S. J., \& Worthington, E. L., Jr. (2010). Comparison of two group interventions to promote forgiveness: Empathy as a mediator of change. Journal of Mental Health Counseling, 32(1), 35-57. 
Stratton, S. P., Dean, J. B., Nooneman, A. J., Bode, R. A., \& Worthington, E. L., Jr. (2008). Forgiveness interventions as spiritual development strategies: Workshop training, expressive writing about forgiveness, and retested controls. Journal of Psychology and Christianity, 27, 347-357.

Strelan, P., \& Covic, T. (2006). A review of forgiveness process models and a coping framework to guide future research. Journal of Social and Clinical Psychology, 25, 1059-1085. doi: 10.1521/jscp.2006.25.10.1059

Subkoviak, M. J., Enright, R. D., Wu, C. R., Gassin, E. A., Freeman, S., Olson, L. M., \& Sarinopoulos, I. (1995). Measuring interpersonal forgiveness in late adolescence and middle adulthood. Journal of Adolescence, 18, 641-655.

Tabachnick, B. G., \& Fidell, L. (2001). Using multivariate statistics (4th ed.). Needham Heights, MA: Allyn \& Bacon.

Wade, N. G., Hoyt, W. T., \& Worthington, E. L., Jr. (2013). Meta-analysis of psychotherapeutic interventions to promote forgiveness. Manuscript under editorial review, Iowa State University. Wade, N. G., \& Meyer, J. E. (2009). Comparison of brief group interventions to promote forgiveness: A pilot outcome study. International Journal of Group Psychotherapy, 59(2), 199-220.

Wade, N. G., Worthington, E. L., Jr., \& Haake, S. (2009). Promoting forgiveness: Comparison of explicit forgiveness interventions with an alternative treatment. Journal of Counseling and Development, 87, 143-151.

Wade, N. G., Worthington, E. L., Jr., \& Meyer, J. E. (2005). But do they work? A metaanalysis of group interventions to promote forgiveness. In E. L. Worthington, Jr. (Ed.), Handbook of forgiveness (pp. 423-440). New York: Brunner-Routledge. 
Worthington, E. L., Jr. (2006). Forgiveness and reconciliation: Theory and practice. New York: Brunner-Routledge.

Worthington, E. L., Jr., Hook, J. N., Utsey, S. O., Williams, J. K., \& Neil, R. L. (2007, October). Decisional and emotional forgiveness. Paper presented at the International Positive Psychology Summit, Washington, DC.

Worthington, E. L., Jr., Hunter, J., Sharp, C., Hook, J. N., Van Tongeren, D. R., Davis, D. E., et al. (2010). A psychoeducational intervention to promote forgiveness in Christians in the Philippines. Journal of Mental Health Counseling, 32(1), 75-93.

Worthington, E. L, Jr., \& Lavelock, C. R., \& Scherer, M. (2012). The path to forgiveness: Six practical sections for becoming a more forgiving person. Virginia Commonwealth University, Richmond, VA.

Worthington, E. L. Jr. Witvliet, C. V. O., Pietrini, P., \& Miller, A. J. (2007). Forgiveness, health, and well-being: A review of evidence for emotional versus decisional forgiveness, dispositional forgivingness, and reduced unforgiveness. Journal of Behavioral Medicine, 30, 291-302. doi: 10.1007/s10865-007-9105-8 
Table 1

Means and Standard Deviations of the Wait-List and Immediate-Treatment Conditions

$\begin{array}{lll}\text { Time } 1 & \text { Time } 2 & \text { Time } 3\end{array}$

\begin{tabular}{|c|c|c|c|c|c|c|}
\hline Measure & M & $\mathrm{SD}$ & M & $\mathrm{SD}$ & $\mathrm{M}$ & SD \\
\hline Wait-List & (Pre1) & & (Pre2) & & (Post) & \\
\hline TRIM_AR & $32.71^{\mathrm{a}}$ & 13.72 & $30.43^{\mathrm{a}}$ & 12.26 & $18.4^{b}$ & 6.10 \\
\hline DFS & $29.95^{\mathrm{a}}$ & 7.88 & $30.86^{\mathrm{a}}$ & 7.82 & $35.40^{\mathrm{b}}$ & 4.66 \\
\hline EFS & $21.52^{\mathrm{a}}$ & 7.88 & $22.48^{\mathrm{a}}$ & 8.23 & $31.6^{\mathrm{b}}$ & 3.62 \\
\hline RFS & $47.05^{\mathrm{a}}$ & 11.62 & $48.00^{\mathrm{a}}$ & 10.50 & $62.65^{\mathrm{b}}$ & 6.64 \\
\hline Immediate-Treatment & (Pre) & & (Post) & & (Follow) & \\
\hline TRIM_AR & $37.45^{\mathrm{a}}$ & 10.85 & $24.00^{\mathrm{b}}$ & 10.54 & $18.74^{\mathrm{c}}$ & 6.58 \\
\hline DFS & $28.15^{\mathrm{a}}$ & 5.96 & $34.00^{\mathrm{b}}$ & 6.00 & $35.68^{b}$ & 3.84 \\
\hline EFS & $18.75^{\mathrm{a}}$ & 4.83 & $26.60^{\mathrm{b}}$ & 8.22 & $30.53^{b}$ & 6.49 \\
\hline RFS & $44.55^{\mathrm{a}}$ & 11.59 & $56.80^{\mathrm{b}}$ & 14.58 & $62.89^{\mathrm{b}}$ & 9.18 \\
\hline
\end{tabular}


Table 2

Benchmark Comparisons of Methods to Deliver the REACH Forgiveness Intervention

\begin{tabular}{|c|c|c|c|c|c|c|c|c|}
\hline Study & $\mathrm{M}_{\mathrm{AGE}}$ & $\begin{array}{l}\% \\
\text { Female }\end{array}$ & Modality & Dose & $\begin{array}{l}\text { Primary } \\
\text { Outcome } \\
\text { Measure }\end{array}$ & $\begin{array}{l}\text { Z Pre- } \\
\text { treatment }\end{array}$ & $\begin{array}{l}\text { Z Post- } \\
\text { treatment }\end{array}$ & $\begin{array}{l}\text { Standardized } \\
\text { Change } \\
\text { Score }\end{array}$ \\
\hline Present study & 19.64 & 78 & Workbook & $7.02 \mathrm{hrs}$ & TRIM_AR & .8298 & -.2201 & -1.0500 \\
\hline Goldman \& Wade, 2012 & 21.1 & 62 & Group & $9 \mathrm{hrs}$ & TRIM_R & .2511 & -1973 & -.5285 \\
\hline $\begin{array}{l}\text { Lampton, Oliver, Worthington, \& } \\
\text { Berry, } 2005\end{array}$ & 21 & $\mathrm{n} / \mathrm{s}$ & Group & $6 \mathrm{hrs}$ & TRIM_AR & -.0101 & -.4949 & -.5051 \\
\hline $\begin{array}{l}\text { McCullough, Worthington, \& } \\
\text { Rachal, } 1997\end{array}$ & 22 & 80 & Group & $8 \mathrm{hrs}$ & $\begin{array}{l}\text { 5-item scale } \\
\text { from EFI }\end{array}$ & .5045 & .2164 & .7209 \\
\hline Sandage \& Worthington, 2010 & 20.8 & 75 & Group & $6 \mathrm{hrs}$ & EFI & -1.3980 & -.9284 & .4695 \\
\hline $\begin{array}{l}\text { Stratton, Dean, Nonneman, Bode, \& } \\
\text { Worthington, } 2008\end{array}$ & 20.9 & 77 & Group & $5-6 \mathrm{hrs}$ & TRIM_AR & .3045 & -.2240 & .5285 \\
\hline Wade, Worthington, \& Hakke, 2009 & 20 & 79 & Group & $6 \mathrm{hrs}$ & TRIM_AR & .7635 & .3419 & -.4216 \\
\hline Wade \& Meyer, 2009 & 48.6 & 77 & Group & $6 \mathrm{hrs}$ & TRIM_R & .3857 & -.2197 & -.6054 \\
\hline Benchmark Average* & 25.58 & 75 & $\mathrm{n} / \mathrm{a}$ & 6.71 & $\mathrm{n} / \mathrm{a}$ & $\mathrm{n} / \mathrm{a}$ & $\mathrm{n} / \mathrm{a}$ & .5285 \\
\hline
\end{tabular}

*Benchmark Average = average of 7 comparison studies that administer the REACH Forgiveness Intervention via group therapy.

TRIM_R = Transgression-Related Interpersonal Motivation Inventory, Revenge subscale $(\mu=8.68, \sigma=4.46$; McCullough, Rachal, Sandage, Worthington, Brown, \& Hight, 1998); TRIM_AR = Transgression-Related Interpersonal Motivation Inventory, Revenge and Avoidance subscales $(\mu=26.82, \sigma=12.81$; McCullough, Rachal, Sandage, Worthington, Brown, \& Hight, 1998); EFI = Enright Forgiveness Inventory ( $\mu=256.66, \sigma=69.43 ;$ Subkoviak, Enright, Wu, Gassin, Freeman, Olson, \& Sarinopoulos, 1995); Scale Developed = 5-item scale developed for use in this study $(\mu=16.8, \sigma=6.7 ;$ McCullough, Worthington, $\&$ Rachal, 1997). 


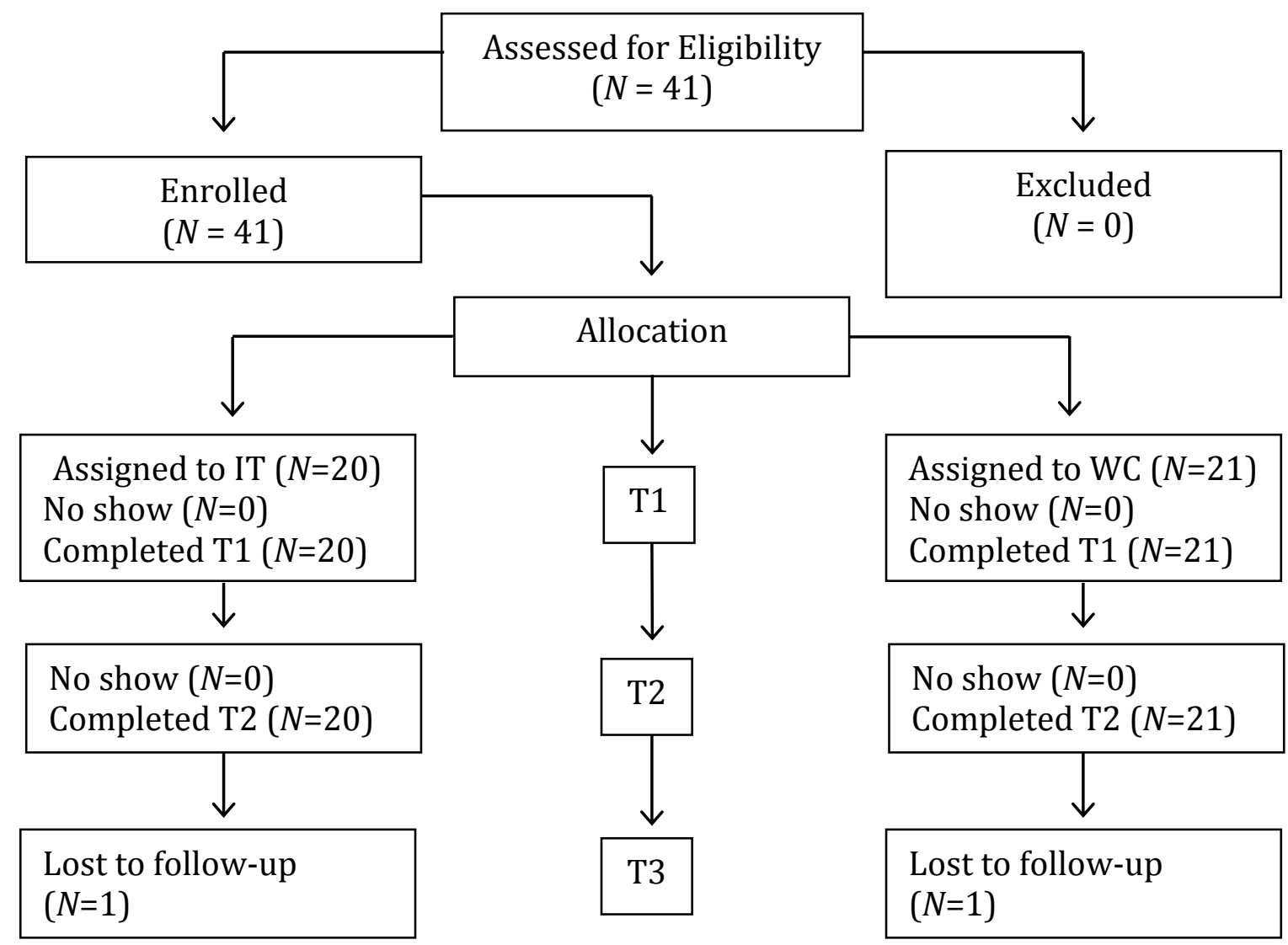

Figure 1. CONSORT Flow Chart that depicting students' progression through the present study. 


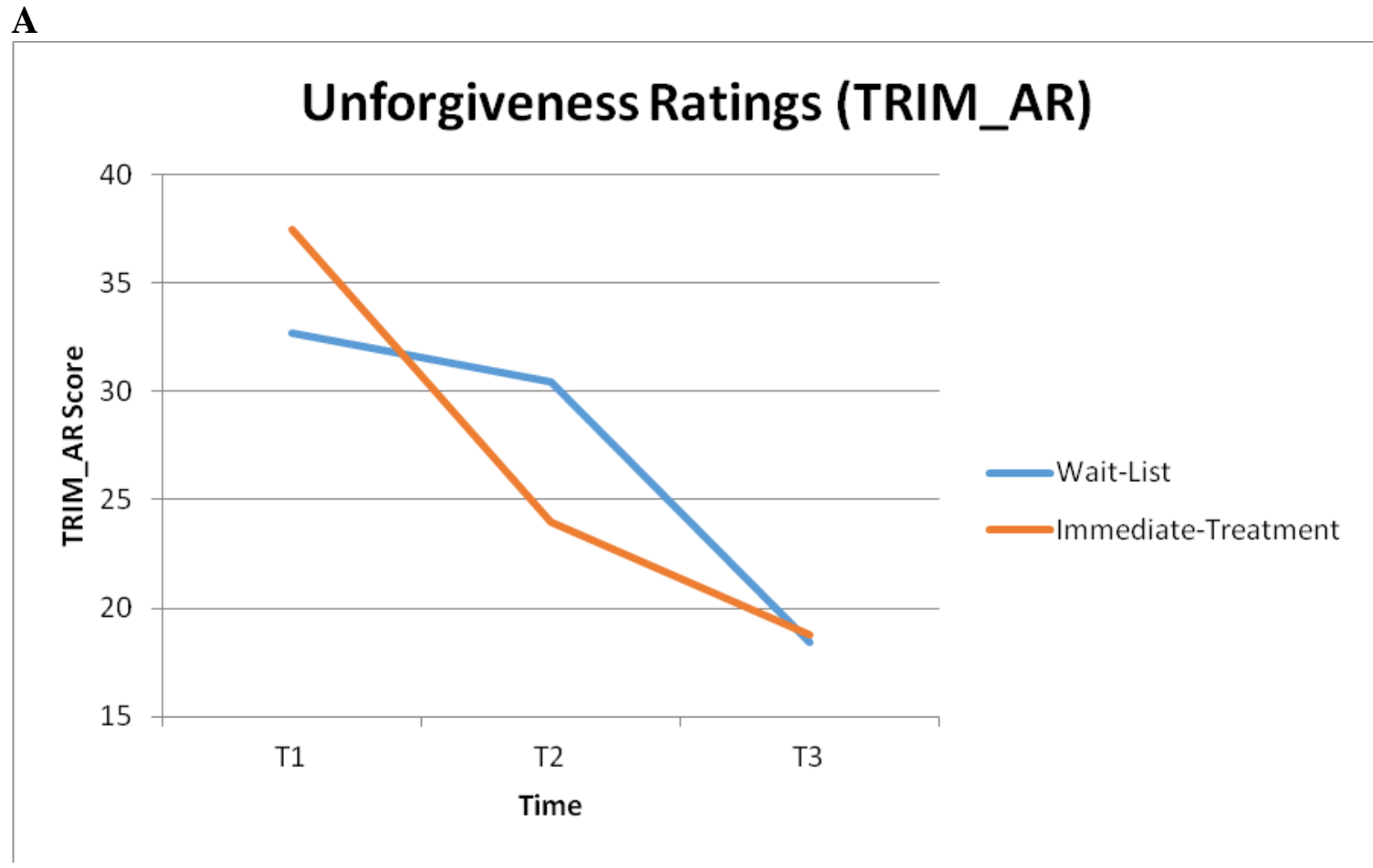

B

\section{Forgiveness Ratings (RFS)}

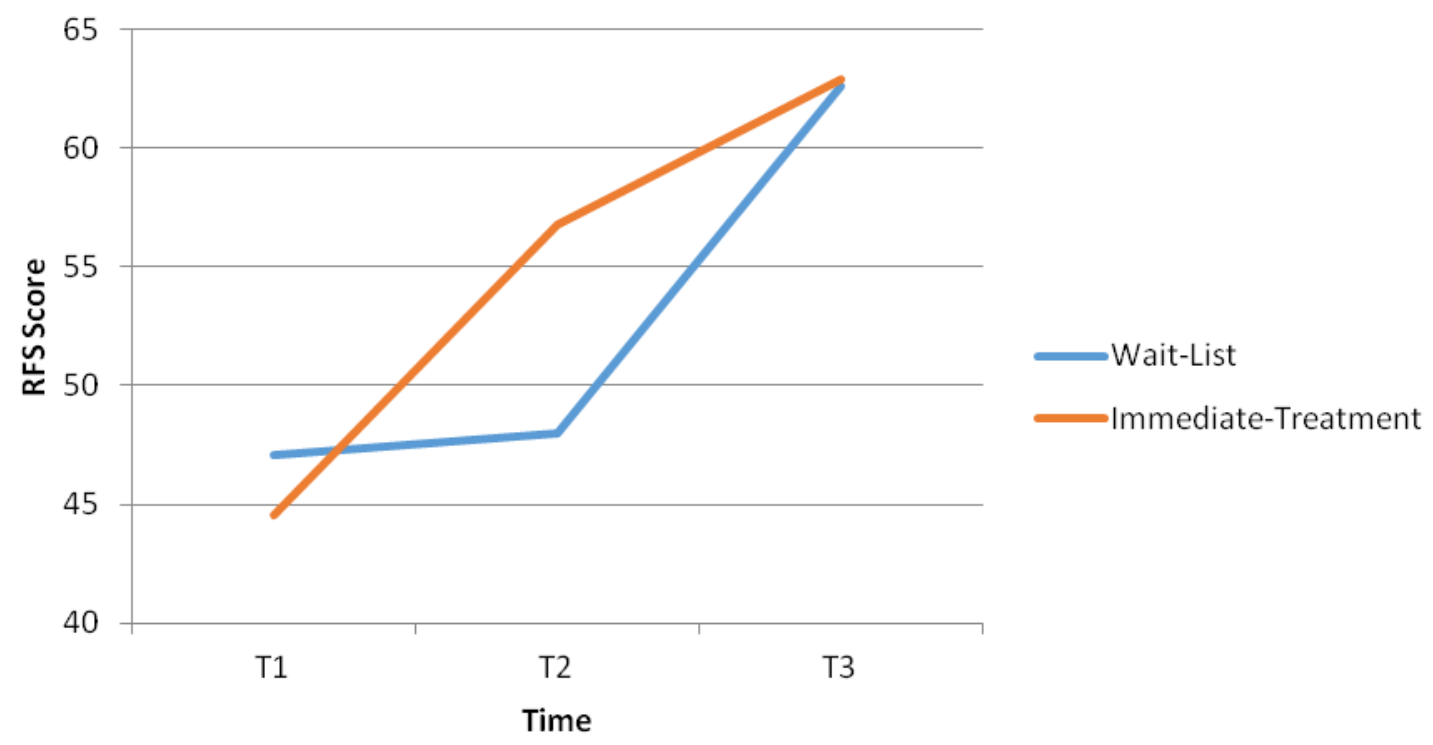

Figure 2. Participants' ratings of unforgiveness and forgiveness over time. TRIM_AR = Transgression-Related Interpersonal Motivations-Avoidance + Revenge (range, 7-60), RFS = Rye Forgiveness Scale (range, 15-75). Participants forgiveness ratings on other measures (i.e., DFS \& EFS) follow a similar pattern. 